\title{
CARNE SUINA: À LUZ DA CIÊNCIA O QUE FAZ MAL É O MITO.
}

\author{
Claudino Ortigara \\ Instituto Federal de Educação, Ciência e Tecnologia do Sul de Minas Gerias - Campus Inconfidentes
}

\section{RESUMO}

A carne suína é a fonte de proteína animal mais consumida no mundo. No entanto, em muitos países e em especial no Brasil o consumo per capita é muito baixo, limitando o crescimento do setor produtivo. Com este trabalho, buscamos uma explicação para entender a resistência da população ao consumo da carne suína.

Fizemos um levantamento de informações que pudessem comprovar as características saudáveis da carne suína e caracterizar a existência de mitos relacionados ao seu consumo. Relacionamos os fatos com as representações sociais, teorias de construção de conhecimentos e conceitos de mitologia. Foi realizada uma pesquisa visando identificar a postura dos médicos com relação a prescrição de dietas envolvendo a carne suína na microrregião de Inconfidentes-MG.

\section{OBJETIVO}

Analisar a constituição, disseminação e possibilidade de destituição dos mitos em relação à carne suína.

\section{HIPÓTESES:}

1 - A publicação de informações sobre características saudáveis da carne suína como destituição do mito, trata-se de abordagem equivocada por considerar que se destituiu o mito, enquanto o que se fez foi apenas provar a existência dele.

2 - Os conceitos atribuídos à carne suína foram construídos ao longo do tempo, com informações que foram verdadeiras umas e sobrevalorizadas outras, num período da história em que predominava o comportamento padronizado, imposto por um sistema vertical de difusão de informações.

3 - Médicos, profissionais cuja área de atuação tem estreita relação com o consumo de alimentos e pertencentes ao grupo de formadores de opinião, parece terem participação decisiva na construção do comportamento das pessoas, com relação ao consumo da carne suína. .

\section{METODOLOGIA}

O trabalho foi desenvolvido seguindo 03 etapas:

a) Revisão bibliográfica com objetivo de identificar de fatos e passagens da história da humanidade que possam ilustrar a constituição de mitos em torno da carne suína. Nesta etapa também analisamos dados científicos que foram produzidos com o objetivo de revelar as características reais da carne suína e, relacionamos com teorias de construção de conhecimento.

b) Aplicação de questionário (entrevista) visando identificar o comportamento mais freqüente do médico em relação à carne suína, diante de um diagnóstico que requer prescrição de dieta alimentar. A metodologia usada foi de "estudo de caso" e a abordagem foi feita em forma de entrevista dirigida. A região de aplicação das entrevistas ficou definida como a microrregião de Inconfidentes-MG, 
localizada no Sul do Estado de Minas Gerais. A população atendida pelos médicos entrevistados é superior a 50.000 habitantes.

Foram identificados três diagnósticos em que se caracteriza a necessidade de prescrição de dieta alimentar: diabetes, hipertensão e cardiopatias. Elaborou-se um rol de alimentos, constituídos de ingredientes, comuns na dieta da população da região de estudo, incluindo-se aí a carne suína. O entrevistado apontou aquelas a que faria restrição na dieta do paciente.

c) Análise final, etapa em que fizemos uma análise das informações obtidas nas etapas anteriores visando-se à produção de inferências e subsídios que possam fomentar ações no sentido de contribuir para destituição dos mitos.

\section{AS REPRESENTAÇÕES SOCIAIS}

A imitação é um modo de interação que permite que um comportamento vá além da ontogênese de um indivíduo, não necessitando, portanto ser reinventado a cada geração. "Aos comportamentos que são adquiridos ontogenicamente na dinâmica comunicativa de um meio social e que são estáveis por várias gerações, chamamos comportamentos culturais" (MATURANA, 1993).

Na biologia há um consenso de que o indivíduo é produto de sua herança genética influenciada pela ação do meio ou pelas circunstancias do meio. O ser vivo depende da sua circunstância para moldar seu comportamento e socializar-se pelo seu agir.

A afirmação de Maturana pode ser usada como explicação científica para o dito popular, "Maria vai com as outras", que por sua vez, não deixa de ser reflexo do comportamento do indivíduo perante o social. É esse comportamento que deverá se repetir nas tomadas de decisão do dia-a-dia de cada um, e constituindo assim um fazer coletivo que pode ser observado nas atividades de lazer, nas formas de se vestir, nos hábitos alimentares, enfim, nos comportamentos que convencionamos chamar sinteticamente de culturais.

No caso em questão, consumo de carne suína, observa-se que em determinadas regiões do mundo como na Europa e no sul do Brasil, o consumo é maior do que na África, América do Norte e norte do Brasil. Não é apenas o comportamento relacionado ao consumo de carne suína que é diferenciado nessas regiões. Outros ingredientes fazem parte da dieta dessas populações, bem como, outras formas de lazer, de vestir, de expressão, outras crenças, enfim, uma série de comportamentos que são comuns à grande maioria da população, mas que não são freqüentes em outras regiões. Os indivíduos pertencentes a determinada comunidade, tendem manifestar de forma intuitiva quase mecânica, comportamento sistematicamente muito semelhante dentro dessa comunidade, quando deparam com a mesma situação. Esse comportamento poderá ser diferente do observado por outras populações diante da mesma situação.

$\mathrm{Na}$ teoria de Moscovici (1982) as representações sociais podem ser entendidas como "um conjunto de conceitos, afirmações e explicações originadas no quotidiano, no decurso de comunicações inter-individuais". São equivalentes aos mitos e crenças nas sociedades tradicionais, podendo ser vistas como versão contemporânea do senso comum.

As representações coletivas, assim chamadas pela sociologia, são um termo explicativo que determina uma classe geral de conhecimento e crenças. Já do ponto de vista da psicologia social, as representações sociais estão ligadas à maneira especial de se adquirir e comunicar conhecimento, criando realidade e senso comum.

\section{Uma arquitetura geral para os seres vivos}

O consumo da carne suína pode ser, em última instância, considerado como produto de uma tomada de decisão. A tomada de decisão a que nos referimos, constitui o tema central de toda nossa discussão. Trata-se de uma ativida- 
de cognitiva. Para melhor compreensão desta atividade usaremos o modelo de Jean François Richard (figura 1) para representar de forma clara o processo cognitivo, pelo menos o suficiente para entender como um indivíduo decide sobre carne de porco ou frango.

As entradas do sistema cognitivo são as situações. No que nos concerne, elas são as informações que são o resultado dos tratamentos dos sistemas sensoriais, no caso dos indivíduos; nos filtros sensoriais sociais, no caso do socius. As saídas do sistema cognitivo são atitudes, conflitos, no caso do socius; e movimentos, gestos e produções lingüísticas, no caso dos indivíduos.

A opção pela proteína animal que será freqüente na dieta de determinada população, no caso do socius; e a opção pela escolha da carne que será colocada no carrinho do supermercado, no caso do indivíduo, são exemplos de comportamentos que completam os exemplos acima citados.

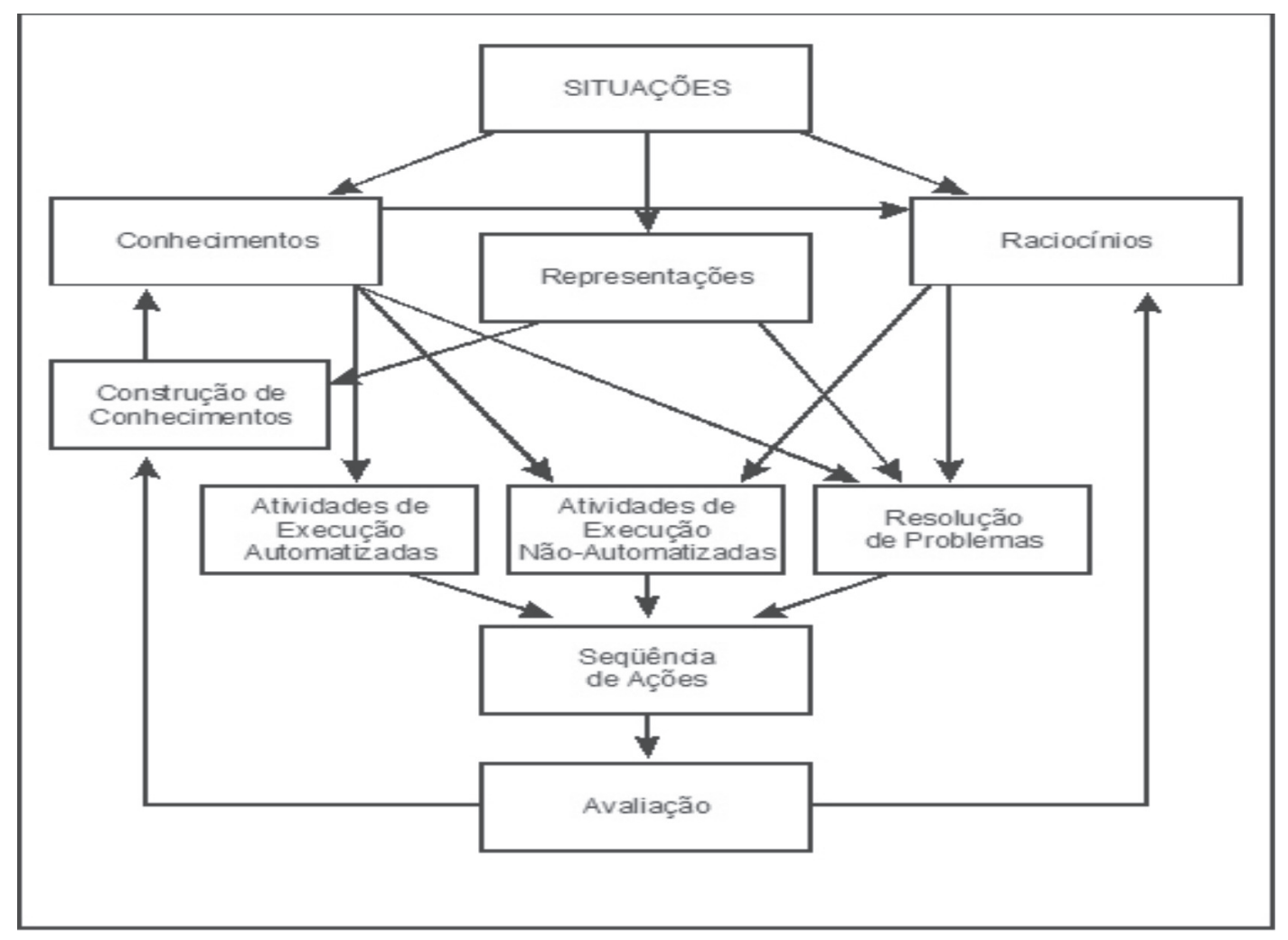

Figura 1. Arquitetura Geral Cognitivista

As representações são construções circunstanciais feitas num contexto particular e com fins específicos: numa situação dada e para fazer face às exigências da tarefa em curso, um texto que se lê, uma ordem que se escuta, um problema a resolver. Sua construção é finalizada pela tarefa e pela natureza das decisões a tomar.

As representações levam em conta o conjunto dos elementos da situação e são, portanto, muito particularizadas, ocasionais e precárias por natureza. É suficiente que a situação mude ou que um elemento não observado da situação seja levado em conta para que a representação seja modificada. Elas são por natureza transitórias: uma vez terminada a tarefa, são substituídas por outras representações ligadas a outras tarefas.

Os conhecimentos são também construções, porém são permanentes e não 
são inteiramente dependentes da tarefa a realizar: são gravados na memória de longo termo e, enquanto não forem modificados, supõe-se que se mantém sob a mesma forma.

Do ponto de vista do funcionamento cognitivo, a diferença entre conhecimento e representações é que: os conhecimentos têm necessidade de serem ativados para serem eficientes; enquanto que as representações são imediatamente eficientes. Isto porque as representações constituem o conteúdo da memória operacional, a saber, as informações gravadas na memória de trabalho $\mathrm{e}$ as informações ativas da memória de longo termo.

Os conhecimentos, ao contrário, são gravados na Memória de Longo Termo (MLT). Nem todas as informações na MLT estão disponíveis. Só uma pequena parte delas as que têm um nível de ativação suficiente ou que são objeto de uma busca bem sucedida na memória.

Aos conhecimentos não lhes atribuímos simplesmente um caráter de verdade.

Eles são verdadeiros ou falsos dependendo do referencial e, portanto, das crenças. O caráter de verdadeiro ou falso dos conhecimentos ou crenças é secundário do ponto de vista psicológico. $\mathrm{O}$ importante é que estejam na memória do indivíduo, tenham sua adesão e possam tornar-se eficientes.

As decisões de ação constituem as produções do sistema cognitivo (suas saídas sob forma de descrição sistêmica). Sua elaboração corresponde a três tipos de tarefas para o sistema cognitivo:

- tarefas de resolução de problemas isto é, situações de elaboração de procedimentos nos quais, esta elaboração, depende da representação da situação;

-tarefas de execução não automatizadas que correspondem a situações para as quais existem procedimentos gerais na memória que devem ser adaptados ao caso particular; - tarefas de execução automatizadas que consistem na utilização de procedimentos específicos.
Ao escolhermos os alimentos que iremos consumir e aqueles que evitaremos, estaremos executando uma tarefa. Essa tarefa requer sucessiva tomada de decisões que são novas pequenas tarefas, como por exemplo: escolher os alimentos que nos são mais palatáveis; aqueles que são "saudáveis"; os não recomendados; os que são limitados por problemas específicos de cada individuo; equacionar o custo; etc...

Se na escolha entre carne suína ou frango, o individuo analisar pela tabela de preços, então estará usando uma informação, e a partir dela, construirá sua representação. Buscará nos seus conhecimentos procedimentais subsídios para inferir e então resolver o problema, ou seja, faz a escolha. Por tratar-se de uma tarefa rotineira, o individuo certamente terá armazenado na sua "caixa" de conhecimentos, um procedimento "pronto" para ser usado na resolução deste problema. Teremos então uma tarefa de execução automatizada.

Esse script que é acionado para o consumo da carne suína, considera informações como as contidas nos livros Levítico da Bíblia Sagrada e Alcorão, que se não são verdades, encontram-se sedimentadas entre os conhecimentos das populações e são determinantes na escolha da carne que será consumida. Não há se quer a necessidade de o individuo ter acesso a essas informações, pois pode tratar-se de um comportamento cultural ontogenicamente adquirido.

Para que essa ação deixe de ser uma atividade de execução automatizada, faz-se necessário mudar a situação. A produção de novas informações sobre os teores de colesterol da carne suína e suas características saudáveis, é muito importante para isso, mas tanto no Brasil como em outras partes do mundo, tais informações não tem sido suficientes. Embora estas informações estejam disponíveis, para a grande maioria da população não são percebidas, portanto não possibilitam a construção de novas representações, novos conhecimentos e não ocorre, portanto a evolução do sistema cognitivo. 


\section{A CONSTRUÇÃO DE UM MITO}

O estudo das teorias de construção de conhecimentos e as representações sociais são muito pertinentes ao estudo da causa e com certeza nos possibilitarão conclusões acerca do assunto. Percebemos no entanto, a falta de um anel de ligação, um nó na rede em determinadas situações. Quando exploramos os aspectos míticos relacionados com a carne suína, não encontramos explicações satisfatórias para determinados comportamentos.

Barthes (1957) atribuiu a constituição dos mitos inúmeros aspectos da realidade, segundo ele, constantemente mascarados pela empresa, pelo cinema, pela arte e pelos demais veículos de comunicação, sempre a serviço de interesse ideológico. Para Barthes, no entanto o mito não é nada além de uma fala. É um sistema de comunicação, é uma mensagem.

Segundo Jung (1995), além da consciência e do inconsciente pessoal, a psique de cada pessoa é constituída por um inconsciente coletivo. $\mathrm{O}$ inconsciente coletivo é a noção par excelence do pensamento de Jung. Este é transpessoal, isto é, não comum a apenas um indivíduo, mas a toda humanidade.

O inconsciente coletivo" é um "fator psíquico partilhado por toda a humanidade". É o sedimento do passado e a possibilidade criativa do amanhã que garante a cada indivíduo, de todas as épocas, uma igualdade de vivência.

O repositório das experiências humanas, desde os mais remotos inícios, o depósito das experiências ancestrais acumuladas ao longo de milhões de anos, o eco dos acontecimentos pré-históricos ao qual cada século acrescenta uma parcela infinitivamente pequena de variações e de diferenciações, Jung denomina de arquétipo.

\footnotetext{
${ }^{1}$ Por coletivo Jung explica no Vol. VI, par. 772: são os conteúdos psíquicos, isto é, representações coletivas na terminologia utilizada por Lévy Bruhl, conceitos gerais, nos termos usados pelas pessoas cultas no direito, na religião, na ciência, etc. e também os sentimentos coletivos de uma sociedade, de um povo ou da humanidade
}

$\mathrm{O}$ arquétipo "corresponde àquela maneira inata de acordo com a qual o leitão ao nascer busca os peitos da porca para mamar, $o$ pinto emerge do ovo, o pássaro constrói seu ninho". Os arquétipos são sistemas vivos de reações e aptidões que determinam as vidas das pessoas. São esses arquétipos que, segundo Jung (1995), formam o inconsciente coletivo que o autor também chama de psique objetiva.

Os arquétipos são numerosos e não são acessíveis à consciência. O que é acessível são imagens arquetípicas percebidas e experimentadas pela pessoa em forma e imagens típicas e universais. Essas imagens arquetípicas são elaboradas simbolicamente de várias maneiras, constituem o conteúdo das mitologias, religiões, lendas, contos de fadas em todas as épocas e também emergem da psique profunda través dos sonhos e visões.

Neste trabalho, que enfoca o consumidor enquanto parte de uma coletividade, fazemos dos mitos a "via régia" para o inconsciente, uma vez que os mitos dos povos são a melhor expressão dos fenômenos da psique. Além do que, o trabalho é uma construção humana coletiva. Os mitos, assim como os sonhos, são símbolos. O símbolo é o intermediador, o mensageiro, entre as duas linguagens diferentes. Ele é um sinal visível de uma realidade invisível. Símbolo, como a etimologia da palavra denota, significa juntar, reunir. Reúne o que antes estava dissociado, a consciência e o inconsciente. Faz a ponte e a aliança entre os dois mundos, torna-os cúmplices.

\section{HISTÓRIA DOS SUÍNOS}

O suíno é motivo de controvérsia desde sua origem. A história sempre contou que a origem dos suínos se deu na China em 4900 anos a.C. (CURVWEN e HATT, 1961). Por outro lado, a história da humanidade conta que o homen deixou de ser nômade para praticar a agricultura, cultivando cereais. 
M. Rosemberg ${ }^{2}$, valendo-se de estudos arqueológicos, questiona essas informações ao afirmar que o homen deixou de ser nômade há 10000 anos atrás para criar animais no cativeiro. $\mathrm{O}$ primeiro desses animais, provavelmente tenha sido o javali, que na descendência daria origem ao porco doméstico. Isso teria ocorrido no leste da Turquia e não na China.

$\mathrm{Na}$ Bíblia Sagrada, livro Levítico capítulo 11 encontramos o título "Os animais que se devem comer" e no versículo 03 ao 07 diz; "Todo o que tem unha fendia e remói entre as bestas, comê-lo-eis. Porem todo que remói e tem unhas, mas não fendida é imundo. E o porco, o qual bem que tem unha fendida, não remói”. Não comereis das carnes de nenhum desses animais, nem tocareis seus cadáveres, por que são imundos para vós"

Moisés, o primeiro legislador da humanidade, proibia o uso da carne suína na alimentação humana como forma de evitar que o povo contraísse doenças parasitárias como a Teníase e a Cistecercose, comuns na época e os suínos eram considerados os principais transmissores ao homem. Viana (1970), descrevendo a evolução dos suínos diz que os árabes, em época muito anterior ao islamismo, tinham eliminado a carne de porco de sua alimentação, talvez influenciados pelos judeus, seus vizinhos e com a adoção da doutrina de Mahomet o seu uso ficou completamente proibido pelo Alcorão. $\mathrm{Na}$ antiga Pérsia, atual Irã, onde os preceitos do Alcorão são praticados, são raros os suínos, e a criação é muito limitada na África pelo mesmo motivo.

Esculturas e baixos relevos, linguagem da antiguidade usada para transmissão de informações e conhecimentos, contendo os porcos como motivo, foram freqüentes em monumentos dos Assírios e Babilônios, expressando o grande apreço que aqueles povos tinham para com esses animais. $\mathrm{Na}$ mitologia grega, encontra-se a "Suivitaurilia"

${ }^{2}$ Citado por Roppa, 1999 uma forma de sacrifício aos Deuses em que se ofertava um suíno, um carneiro e um touro. $\mathrm{O}$ prestígio dos suínos entre esse povo é evidenciado pelo fato de que só se ofertava aos Deuses àquilo que se considerava melhor, e que mais pudesse agrada-los. Na ilha de Creta acreditava-se que uma porca havia amamentado o Deus Júpiter, crença que serviu para que o porco fosse divinizado por aquele povo.

No Império Romano, há uma série de citações exaltando a carne suína. Na Gália durante muito tempo as moedas tiveram a efígie de um javali como forma de expressar prosperidade.

Joana d'Arc, figura importante da história e referenciada por muitas pessoas de sua época, em determinado período de sua vida teve alucinações. Essas alucinações foram, na época, consideradas conseqüências de cisticercos calcificados que foram encontradas na necropsia de sua cabeça, e a origem dos cisticercos fora atribuída ao consumo de carne de porco. A notoriedade de Joana d'Arc fez com que essas informações fossem amplamente difundidas provavelmente permeadas de ênfase emocional.

Os livros de Moisés e o Alcorão, se constituíram na época, em importantes instrumentos de transmissão de informações sobrevivendo geração após geração, chegando até os dias de hoje.

\section{"Essa superstição contra o porco passou atenuada, aos nossos antigos sertanejos, que não pronunciavam o nome do porco sem pedir licença e, mesmo assim, utilizando uma alcunha que contornava o embaraço. A alcunha de sua invenção é "o cabeça baixa". (DOMINGUES, 1941 grifo do autor)}

A origem dessa ojeriza ao suíno foi explicada, no caso dos Egípcios, por Ellien ${ }^{3}$ que escreveu: "o porco é de tal modo voraz que não poupa nem seus filhos e devora cadáveres

${ }^{3}$ Citado por Domingues, 1941. 
No Brasil, em meados deste século, com o advento da mecanização agrícola, eis que surge a soja como alternativa para agricultura que, multiplicando seus adeptos, se constituiu numa das principais culturas nacionais, alicerce de grandes grupos agroindustriais produtores de óleo de soja. São então, veiculadas na mídia sucessivas campanhas de marketing realçando as características saudáveis do óleo de soja, enfatizando principalmente a ausência de colesterol nas gorduras vegetais em detrimento da banha de porco. A praticidade no uso do óleo de soja e as anunciadas características saudáveis, contrastando com a propagada nocividade da carne de porco serviram para afirmar o conceito negativo da carne suína.

Atualmente a grande concentração de animais ocasionada pela produção em grande escala tem gerado problemas ambientais. A produção de grandes volumes de dejetos é uma característica da criação dos suínos. Isto, no contexto atual, em que se repudiam compulsoriamente atividades que causam danos ao meio ambiente, significa o fortalecimento do conceito de "imundo" do suíno.

\section{RESULTADOS E DISCUSSÃO}

Até medos do século XX, a gordura foi considerada como um dos principais produtos da suinocultura, atendendo às exigências do mercado neste período. A espessura do toucinho dos suínos da época era de 50 a $60 \mathrm{~mm}$, e o suíno apresentava 40 a $45 \%$ de carne magra na carcaça. Hoje, se encontram no mercado suíno com mais de $60 \%$ de carne magra e de 10 a $15 \mathrm{~mm}$ de espessura de toucinho na sua carcaça.

O baixo consumo de carne suína, no Brasil, está relacionado a conceitos errôneos que ela foi incorporando no decorrer da história da humanidade. Trabalhos científicos recentes, mostram que muitos conceitos não são verdadeiros, isto no entanto, não tem contribuído para mudanças no comportamento da população em relação ao consumo.

Embora essa problemática esteja, há muito tempo, afligindo o segmento da suinocultura no Brasil, passou a despertar maior interesse a partir de 1993, com a publicação do resultado de uma pesquisa realizada na UNICAMP, por Neura Bragagnolo (1993), que mostra os baixos índices de colesterol da carne suína, em relação às fontes de proteína animal

Tabela 01 - Teores de Colesterol (mg/100g)

\begin{tabular}{|l|c|c|}
\hline \multicolumn{2}{|c|}{ Teores de Colesterol (mg/100g) } \\
\hline Alimento & Cru & Cozido \\
\hline Frango & 58 & 75 \\
\hline Carne Branca & 80 & 124 \\
\hline Carne escura 80 124 104 & 139 \\
\hline Pele 104 139 & Carne Suína \\
\hline \multicolumn{3}{|c|}{} \\
\hline Bisteca & 49 & 97 \\
\hline Lombinho & 59 & 69 \\
\hline Pernil & 50 & 82 \\
\hline Toucinho & 54 & 56 \\
\hline \multicolumn{2}{|c|}{ Carne Bovina } \\
\hline Contra filé & 51 & 66 \\
\hline Coxão duro & 56 & - \\
\hline Coxão mole & 50 & - \\
\hline Músculo & 52 & 67 \\
\hline Peito & 52 & - \\
\hline
\end{tabular}

FONTE: Neura Bragagnolo, Faculdade de Engenharia de Alimentos da UNICAMP, 1993 
Os resultados obtidos por Bragagnolo (1993), foram semelhantes a dados anteriormente anunciados na Europa, no Canadá e nos Estados Unidos. Nos Estados Unidos, os dados foram revelados pela Associação Americana do Coração, e naquele país, bem como no Canadá, a carne suína tem a aprovação bem como a recomendação de instituições de cardiologia. Na Europa e na América do Norte, esses trabalhos podem não ter tido a repercussão que se observou no Brasil, provavelmente porque a restrição que a carne suína tem nessas regiões é bem menor.

Uma pesquisa Realizada pela Associação Brasileira dos Criadores de Suínos (ABCS) em 1994 mostra que 35\% da população brasileira considera a carne nociva e perigosa e $55 \%$ tem restrições pelos seus teores de gordura e colesterol. O principal atributo apontado foi o sabor, 92\% dos entrevistados disseram ser este o ponto forte e principal atrativo que a carne suína apresenta.

Roppa (1999) enfatizando os baixos teores de colesterol aborda ainda outras características da carne suína que imaginou pudessem servir para ajudar a construir uma imagem favorável deste produto para com os consumidores, tais como:

-Relação gorduras saturadas e insaturadas: $65 \%$ das gorduras dos suínos encontram-se na forma insaturada e $35 \%$ saturada. Quanto maior o teor de gordura insaturada, mais saudável o alimento.

-Carne magra: A carcaça do suíno criado comercialmente hoje possui entre 56 e $58 \%$ de carne magra. De toda a gordura do suíno, $70 \%$ é subcutânea, compondo a camada de toucinho. A gordura intramuscular da carne suína varia 1,1 a $2,4 \%$, sendo esses índices iguais a da carne de frango e inferiores à da carne bovina ( $2,5 \%)$ e ovina $(6,5 \%)$.

A grande variedade de produtos originados dos suínos e usados na medicina humana, e principalmente o uso de órgãos como pele e válvulas cardíacas para transplantes, deve ser interpretado como resultado da similaridade que há entre os organismos humano, e suíno o que deveria conspirar a favor do consumo.

A similaridade observada entre a fisiologia dos suínos e a humana, tornam os suínos os principais candidatos a parceiros da medicina nos xenotransplantes.

\section{O MITO DO COLESTEROL}

Pela pesquisa realizada pela $\mathrm{ABCS}$, a restrição da população ao consumo da carne suína é de $90 \%$. Fica evidente também, que o binômio gordura/colesterol é o principal fator de rejeição, por isso consideramos necessária a discussão desses elementos e outros que entendemos contribuem para rejeição do consumo.

O colesterol é responsável por funções vitais do organismo, e segundo a Sociedade Brasileira de Cardiologia, do ponto de vista químico não se trata de uma gordura. Ele é um álcool monoídrico não saturado, fundamental para o homem porque faz parte da constituição da membrana que reveste as células dos tecidos e constitui matéria prima para a fabricação de ácidos biliares, hormônios e vitamina $\mathrm{D}$. Portanto, ninguém pode viver sem colesterol.

No sangue, o colesterol pode estar livre ou fazendo parte das chamadas lipoproteínas (aglomerado de colesterol, proteínas e gorduras que circulam pelas artérias e veias). Do ponto de vista prático nos interessam dois tipos dessas lipoproteínas: a LDL (Low Density Proteins ou lipoproteínas de baixa densidade) e as HDL (High Density Lipoproteins ou lipoproteínas de alta densidade). O colesterol que faz parte das LDL é o que participa da formação das placas de arteriosclerose que obstruem as artérias. Quando ele é absorvido pelos macrófagos que são células sanguíneas, elas se transformam nas chamadas células espumosas que marcam o início do processo de arteriosclerótico. Sua elevação é portanto, indesejável e deve ser combatida. Já o colesterol contido nas lipoproteínas HDL é o bom colesterol. Ele não participa do processo de obstrução das artérias e tem ainda um efeito protetor. Essas lipopro- 
teínas, na realidade retiram o colesterol dos tecidos e o levam para o fígado onde é eliminado ou reaproveitado. A essa ação chama-se de transporte reverso do colesterol que tem ação anti-arteriogênica. Portanto, quanto maior o teor dessas lipoproteínas HDL ou de alta densidade mais se evita a obstrução arterial pela arteriosclerose.

Tabela 02 - Teores de colesterol, resultado de diferentes fontes de pesquisa

\begin{tabular}{|l|c|c|c|c|c|}
\hline \multirow{7}{*}{ Tipo de Carne } & \multicolumn{5}{|c|}{ Fontes } \\
\cline { 2 - 7 } & $\mathbf{1}$ & $\mathbf{2}$ & $\mathbf{3}$ & $\mathbf{4}$ & Média \\
\hline Carne suína (mg/100g) & 78 & 79 & 69 & 65 & 72,8 \\
\hline Lombo cozido & & & 82 & 65 & 73,5 \\
\hline Pernil cozido & \multicolumn{5}{|l|}{} \\
\hline Carne de frango (mg/100g) & 84 & 84,8 & & & 84,4 \\
\hline Peito cozido, sem pele & 92 & 95,3 & & & 93,6 \\
\hline Coxa cozida, com pele & \multicolumn{5}{|l|}{} \\
\hline Carne Bovina (mg/100/g) & 84 & 84 & & & 84 \\
\hline Filé mignon, cozido
\end{tabular}

FONTE: Adaptado por Roppa, 1996, na web, www.suinopaulista.com.br ,Acessado em Agosto de 2000, sendo:

1- NPPC, National Pork Producers Council and National Pork Board.

2- USDA, Agricultural Handbook 8-10, 1992

3- Brogagnolo, N. 1993

4- Universidad Nacinal de Nutrición, México, 1994

É desejável, portanto, o aumento dos níveis de HDL na corrente sanguínea. O aumento dos níveis de HDL pode ser obtido através de exercícios físicos, eliminação de fatores como tabagismo e obesidade, alimentação rica em fibras vegetais, e aumento do consumo de alimentos com maior concentração de HDL, como a carne suína, entre outros.

O aumento da taxa de colesterol na corrente sanguínea ocorre por uma disfunção orgânica, onde o organismo perde sua capacidade de controle. As ingestões de alimentos ricos em colesterol ou gorduras podem, no entanto, se transformar em fator de pré-disposição do aumento da taxa de colesterol. É daí que surge toda a prevenção contra a ingestão de alimentos gordurosos e nesse raciocínio que se inclui a carne suína.

$\mathrm{Na}$ Tabela 02 observamos que nos cortes de carne analisada por diferentes fontes do mundo, mostram que a carne suína se destaca pelos baixos índices de colesterol.

\section{O MITO DA GORDURA}

O fato de o suíno já ter sido a principal fonte de lipídios para dieta humana, tal informação que se encontra sedimentada na memória de grande parte da população como sinônimo de gordura.

A qualidade das gorduras é medida pela composição química dos seus elementos básicos, os ácidos graxos. Eles, basicamente, se dividem em saturados, monoinsaturados e poliinsaturados. Os saturados incrementam o colesterol no sangue, enquanto que os poliinsaturados se opõem a tal inconveniente. Já os monoinsaturados não atuam nesse nível. O que define a melhor ou pior qualidade de um alimento em sua relação com o colesterol é a relação poliinsaturados/saturados. Quanto maior essa relação, mais aconselhável será o seu consumo. $\mathrm{O}$ indicado para o conjunto da dieta está entre 0,8 e 1,0 .

Nos suínos e aves, esta relação está entre, 0,3 e 0,8 , enquanto que nos bovinos é de 0,1 e nos ovinos de 0,04 . 
Tabela 03 - Quantidade de gordura total nos principais cortes de carnes, determinada por diferentes fontes.

\begin{tabular}{|l|c|c|c|c|c|c|}
\hline \multirow{2}{*}{ Tipo de Carne } & \multicolumn{7}{|c|}{ Fontes } \\
\cline { 2 - 6 } & $\mathbf{1}$ & $\mathbf{2}$ & $\mathbf{3}$ & $\mathbf{4}$ & Média \\
\hline Carne suína (mg/100g) & 7,5 & 7,12 & 5,9 & 6,2 & 6,7 \\
\hline Lombo cozido & & & 4,7 & 6,2 & 5,5 \\
\hline Pernil cozido & \multicolumn{7}{|c|}{} \\
\hline Carne de frango (mg/100g) & 3,5 & 3,5 & 3,5 & & 3,5 \\
\hline Peito cozido, sem pele & 15,3 & 10,8 & & & 13,0 \\
\hline Coxa cozida, com pele & 10,0 & 10,0 & & & 10,0 \\
\hline Carne Bovina (mg/100/g)
\end{tabular}

FONTE: Adaptado por Roppa, na web, www.suinopaulista.com.br ,Acessado em Agosto de 2000, sendo:

1- NPPC, National Pork Producers Council and National Pork Board.

2- USDA, Agricultural Handbook 8-10, 1992

3- Canadian Nutrition File, 1991 e University of Moncton, 1994

4- Universidad Nacinal de Nutrición, México, 1994

Segundo Roppa (1999), os níveis de gordura presentes na carne suína são semelhantes, quando não inferiores aos encontrados nas carnes de frango e bovina. Outro aspecto a ser observado é o de que, a gordura dos suínos concentra-se nos tecidos subcutâneos formando a camada de toucinho. Isto possibilita a opção do consumo ou não por parte dos indivíduos. No entanto, recomendações da American Heart Association, indicam que o alimento a ser ingerido diariamente, deve atender os requerimentos de energia do organismo com $25 \%$ das calorias fornecidas pelas gorduras.

\section{O MITO DA CISTICERCOSE}

A cisticercose é uma doença parasitária que ocorre, quando o indivíduo "hospeda" larvas da Taenia solium. As larvas constituem uma fase intermediária do ciclo de vida do parasito. Quando o homem "hospeda" a forma adulta do verme, a doença denomina-se Teníase. Quando os suínos eram criados em sistemas extensivos ou semi-intensivos e tinham acesso a solo, vegetais e normalmente as condições sanitárias eram deficitárias, a incidência de cisticercose nos suínos era freqüente. Por isso, quando a cisticercose é diagnosticada na espécie humana, o caso acaba sendo relacionado aos suínos.

Quando o ser humano alimenta-se de carne suína contaminada com cisticercos, ele irá desenvolver a forma adulta do verme, que se aloja no intestino, quase sempre um único exemplar se desenvolve, e no caso, a doença é denominada de Teníase, popularmente conhecida como "solitária".

Para contrair a cistecercose ou neurocistecercose, o homem tem que ingerir um ovo do verme adulto. Para que os suínos desenvolvam a Taenia adulta e sejam veículos de disseminação teriam que ingerir os cisticercos, alimentando-se de companheiros ou humanos contaminados, possibilidade mais do que remota. Os sistemas atuais de criação de suínos impõem aos animais condições de completo confinamento, que praticamente anulam a possibilidade de contaminação.

\section{POSTURA DOS MÉDICOS COM RELAÇÃO À CARNE SUÍNA}

A pesquisa realizada junto aos médicos nos proporcionou elementos que possibilitam a visualização da postura médica de acordo com os alimentos que foram sugestivamente, questionados pelo paciente. 
Diante de um diagnóstico de uma doença, foi apresentada ao médico uma relação com 23 alimentos aos quais ele se manifestou diante das opções: "pode"; "evitar"; "não pode".

Para o diagnóstico de diabetes, apenas as saladas de folhas foram prescritas com unanimidade e o inverso coube ao toucinho suíno (torresmo) com nenhuma indicação positiva.

Para o diagnostico de hipertensão, tivemos 08 casos em que a prescrição foi unânime, às vezes seguida de observações tais como: pouco sal, de preferência grelhado etc. No caso destaca-se o fato de que entre as unanimidades estão o peito e a coxa de frango, fontes de proteína animal e objeto de comparação com a carne suína nas tabelas $01 \mathrm{e}$ 02. Dois alimentos não receberam nenhuma indicação de "pode" para dieta de hipertensão; o ovo frito e novamente o torresmo.

No diagnóstico de cardiopatias 06 foram os alimentos que não tiveram nenhuma restrição na prescrição; novamente ovo frito e torresmo não obtiveram nenhuma indicação de "pode".

O questionário previu a possibilidade de o médico fazer comentários sobre o alimento em questão. Foram comuns as observações de pouco sal para uso de hipertensão e a restrição na quantidade de massas e arroz para diabéticos. A carne de frango, peito e coxa, recebeu 04 comentários "sem pele". Isso representa $8,33 \%$ do total de oportunidades. O toucinho apareceu uma vez, com o comentário "com restrição", após uma postura de "não pode". Para um diagnóstico de cardiopatia, o pernil recebeu o comentário de que "tem mais gordura do que o lombo", justificando uma postura de evitar, enquanto o lombo era prescrito.

O alimento saladas de folhas não recebeu nenhuma restrição independente do diagnóstico. As frutas e o feijão vêm na seqüência com poucas restrições. O ovo frito e o torresmo são os vilões da alimentação, segundo a clientela entrevistada. Foram os que sofreram as maiores limitações da inclusão em dietas.

Avaliação de uma dieta alimentar leva em consideração uma série de fatores. Muitos deles sequer citamos, outros foram ou ainda serão superficialmente abordados. O nosso foco está concentrado no alimento, de forma isolada. Isso pode, por vezes, levar a conclusões simplistas, o que não significa que não entendemos a necessidade de se interrelacionar outros fatores na prescrição da dieta. Nos resultados obtidos, observamos que muitos alimentos têm avaliação completamente diferente entre um e outro medico. Como é o caso da margarina, para o diagnóstico de cardiopatia. Enquanto $25 \%$ dos médicos dizem não poder fazer parte da dieta, $37,5 \%$ a recomendam e outros tantos sugerem evitá-la. Este é um exemplo de que enquanto alguns alimentos, como as saladas de folhas e as frutas, são consenso de recomendação, o toucinho (torresmo) e ovo frito são consenso de exclusão, outros tantos tem postura médica completamente heterogênea.

Os dados colhidos no diagnóstico de cardiopatia sobre a inclusão do lombo suíno e do pernil na dieta, são claros e conclusivos no sentido de que a carne suína tem tratamento diferenciado pelo grupo entrevistado. O pernil suíno tem $25 \%$ de "pode", $25 \%$ de "não pode" e $50 \%$ de "evitar". O lombo por sua vez tem $37,5 \%$ de aprovação na dieta, $37,5 \%$ de evitar e $25 \%$ de orientações para sua exclusão. Outros fatores relacionados à prescrição da dieta podem ter interferido na opinião dos médicos, o que supomos tenha ocorrido também com as outras classes de alimentos que, no entanto, não tiveram a postura difusa observada neste caso.

Da forma como foi proposta nossa hipótese inicial sobre a influencia dos médicos, como segmento formador de opinião, ela se confirmou. Cremos que o comportamento observado que tende para evitar a inclusão da carne suína nas dietas alimentares, influencie a formação do conceito indevido da carne suína. Uma análise nas tabelas de teores de colesterol 
(Tabelas 01 e 02) e quantidade de gordura total (tabela 03), observamos que a coxa de frango possui mais colesterol e gordura do que o peito de frango, e bem mais do que o pernil e o lombo suíno.

Observou-se também que o comportamento dos médicos entrevistados foi exatamente o mesmo para coxa e peito de frango. Ou seja, a coxa é associada à imagem saudável do frango. O pernil e o lombo, seguidas as composições observadas nas tabelas citadas, deveriam ter menos restrição do que a coxa de frango. Concluímos que, o pernil e o lombo são associados a imagens dos suínos que têm carne gordurosa e rica em calorias.

Os resultados observados sugerem um conflito entre as informações disponibilizadas e os "conhecimentos" armazenados na memória de longo termo dos médicos. Essa observação é importante na medida em que pode ser generalizada para outros segmentos sociais. As novas informações devem originar novos raciocínios e novas representações mentais, que deverão culminar com a produção de novos conhecimentos. As novas tecnologias de informação tendem a promover o conhecimento coletivo. A busca por informações sobre as características da carne suína, nos revelou um crescente aumento de publicações nesse sentido. A associação das observações com as vantagens sócioeconômicas projetadas pela expansão da suinocultura, nos permite inferir sobre a redução gradativa do nível de resistências ao consumo da carne suína.

\section{CONCLUSÃO}

Os problemas relacionados ao consumo de carne suína começaram a se constituir na antigüidade, como se observa nas passagens do Livro de Moises e Alcorão, que escritos a partir das informações disponíveis naquela época, foram e ainda continuam sendo para parte da população, verdades absolutas. Essas passagens da história envolvem aspectos religiosos e emocionais por parte do indivíduo, no processo de escolha da sua fonte protéica de origem animal que irá compor sua dieta. Para uns a idolatria à carne suína, pois foram alimentos dos deuses, para outros verdadeira ojeriza. E assim foram se constituindo os comportamentos dessas populações, que na dinâmica comunicativa de um meio social foram sendo adquiridos ontogenicamente pelas gerações subseqüentes. De acordo com o conceito de Maturana (1992), concluímos que se trata de um comportamento cultural.

O comportamento relacionado ao consumo da carne é, portanto, uma representação social (MOSCOVICI), correspondente aos universos consensuais, estimulados e fortalecidos pela consciência coletiva.

A escolha da carne que iremos consumir, é uma decisão de ação, é uma produção do sistema cognitivo de elaboração correspondente a uma tarefa de execução automatizada. Assim se explica o comportamento de mais da metade dos médicos entrevistados neste trabalho, em excluir a carne suína das dietas de seus pacientes. Da mesma forma explica-se, porque o comportamento com relação à coxa de frango não foi diferente da do peito, mesmo tratandose de produtos com características comprovadamente diferentes. A ação do médico parte de uma imagem mental em que o frango é "saudável" o suíno "nem tanto".

Conclui-se facilmente a partir do fato, de encontrarmos muitos relatos na história da humanidade envolvendo o suíno, que eles têm uma co-participação na história dos humanos, como se desempenhassem um papel de coadjuvantes. A História nos revela as passagens que envolvem figuras relevantes de cada época, que nos permitem imaginar inúmeras outras ocasiões, principalmente envolvendo as crenças e as religiões em que os suínos estão presentes, e não são relatadas. A reprodução deste contexto através de anos e anos de história, permitiu a sedimentação e a formação dos arquétipos de acordo com o conceito de Jung. Os arquétipos explicam o 
“padrão de comportamento" que é observado nas diferentes culturas

No desequilíbrio entre o consciente e o inconsciente, está a explicação para o fato de algumas pessoas se sentirem "mal" após o consumo de carne suína. $\mathrm{O}$ fato dos arquétipos não serem acessíveis à consciência e terem linguagem própria, somente poderão ser "trabalhados" através desta linguagem. As publicações de dados científicos, comprovando as características saudáveis da carne suína, não atingem os arquétipos.

Isso nos leva a concluir que se trata de um problema psicossomático, e desta forma deve ser tratado.

Conforme observamos, o suíno produzido e disponibilizado para população é completamente diferente do suíno de antigamente. Esta deve ser a tônica das campanhas de marketing e divulgação da carne suína. A adoção desta estratégia possivelmente nos levará a constituição de um novo arquétipo, onde deverá ser alojada a nova imagem mental para carne suína. A eficiência da estratégia tenderá ser mais eficiente, quanto menos permitir transparecer interesses dos indivíduos relacionados ao setor produtivo da suinocultura. A divulgação das características saudáveis da carne suína deverá ser na forma notícias, informação científica, etc.

A criação de um novo arquétipo que abrigue a nova imagem dos suínos, permitirá que caia no esquecimento o arquétipo constituído na antiguidade.

As inferências que produzimos até aqui, nos permitem sintetizar algumas conclusões com relação as hipóteses levantadas no início deste trabalho:

a) Os dados e informações científicas amplamente abordados por este trabalho, em que são evidenciadas as características saudáveis da carne suína servem para caracterizar o mito em si.

b) Comprova-se que o segmento social formado pelos médicos da microrregião de Inconfidentes-MG, tem comportamento difuso, em relação à carne suína, na prescrição de dietas alimentares. $\mathrm{O}$ fato de pertencerem a um reconhecido grupo social de formadores de opinião, notoriamente muito importante no caso em questão, eles têm forte participação na manutenção do mito.

c) Os suínos que são ofertados ao mercado consumidor atualmente, são muito diferentes dos de antigamente, quando da formação do mito. A evolução genética e as condições de criação, permitem oferecer um produto totalmente renovado, seguramente saudável e sem riscos à população.

d) $\mathrm{O}$ fato de, durante muito tempo, suíno ter sido a principal fonte de lipídios da dieta humana, esta informação encontra-se sedimentada na memória de longo termo da grande parte da população e assim participa da tomada decisão com relação ao consumo da carne suína.

e) Uma combinação de fatores, tais como: aumento do volume de informações disponibilizadas; novas tecnologias de informação; vantagens sócio-econômicas vislumbradas pelo crescimento da suinocultura; período histórico de valorização dos conhecimentos; pré-disposição dos indivíduos à mudanças de paradigma, entre outros, constituem um panorama favorável ao desencadeamento de um processo de desmistificação da carne suína.

Finalmente concluímos que investir na divulgação das características saudáveis da carne suína, como produtos da ciência para melhoria das condições de vida da população, promoverá o aumento do consumo por parte da população brasileira e então desencadeará um processo de benefícios sócio-econômicos significativos, que são peculiares da suinocultura.

\section{REFERÊNCIAS BIBLIOGRÁFICAS}

BARTHES, Roland. Mitologias. São Paulo, Bertrand Brasil, 1993.

BIBLIA SAGRADA. Livros LEVITICO e DEUTENOMIO, de Acordo com Vulgata Latina e Tradução de Antonio Pereira Figueiredo, Novo Brasil Editora LTDA, São Paulo, 1982 
BRAGNOLO, N. Determinação dos Níveis de Colesterol em Carnes, Ovos e Macarrão com Ovos, FEA, UNICAMP, 1993. In revista da Carne n ${ }^{\circ} 222$, p. 82.

CAMPBELL, Joseph. O poder do Mito, São Paulo, Editora Ave Maria, 1998

CURWEN, E. C. e HATT, G., The origin of agriculture in Plogh and Pasture. The Early History of Farming. Callier Books. New Yor k..NY 1961

DOMINGUES, Otavio. Introdução a Zootecnia. Rio de Janeiro. Edições Sai,1941.

FIALHO, F. A. P., SANTOS, N. dos (1994) - A general architecture for simulating complex systems able of auto-organization. In: Artificial Neural Networks in Engineering Conference.

FIALHO, Francisco A.P., A modelagem cognitiva na concepção de sistemas de produção. Florianópolis: UFSC, 1992. Dissertação (Mestrado em Engenharia da Produção) - Programa de Pós Graduação em Engenharia da Produção. UFSC. 1992.

JUNG, Carl Gustav. Símbolos de Transformação: uma analise dos prelúdios de uma esquizofrenia. Petrópolis, Vozes, $3^{\text {a }}$ Edição, 1995

MATURANA, H. (1990) - Desde la Biologia a la Psicologia. Chile: Fundación Synthesis, 1993.

MOSCOVICI, S. (1982) - Sobre relações sociais. École des Hautes Etudes en Sciences Sociales: Paris. (resumo)

RICHARD, J.-F. (1990) - Les Activités Mentales. Paris: Armand Polin, 1990.

ROPPA, L. Atualização sobre níveis de colesterol, gordura e calorias da carne suína, in www.suinopaulista.com.br/textos , 1999. 